\title{
Residual Stresses in Transparent Glassceramics and Their Evolution During Step-by-Step Annealing
}

\author{
Igor Matyash, Irina Minailova, Boris Serdega, Volodymyr Maslov, Nataliya Kachur
}

V. Lashkaryov Institute of Semiconductor Physics NAS of Ukraine, Kyiv, Ukraine

\author{
Email address: \\ bserdega@isp.kiev.ua (B. Serdega)
}

\section{To cite this article:}

Igor Matyash, Irina Minailova, Boris Serdega, Volodymyr Maslov, Nataliya Kachur. Residual Stresses in Transparent Glassceramics and Their Evolution During Step-by-Step Annealing. International Journal of Materials Science and Applications. Vol. 4, No. 5, 2015 , pp. $288-292$. doi: $10.11648 /$ j.ijmsa.20150405.12

\begin{abstract}
Non-homogeneous cooling of glassceramics in the process of manufacturing brings about residual thermal stresses in bulk. Their evolution under annealing has been investigated by means of the method of modulation polarimetry. A 2D image enabled us to obtain tomograms of the distribution describing the value and sign of the uniaxial stress in the sample plane, which is parallel to the direction of a thermal flux. Relaxation of residual stresses has non-monotonic dependence versus the value of the annealing temperature. The nature of its origin has been discussed. Found in this work is coordinate dependence of a thermoelasticity coefficient, as well as its correlation with a stress function.
\end{abstract}

Keywords: Thermoelasticity, Anisotropy, Birefringence, Modulation Polarimetry, Residual Stresses, Stress Optic Coefficient

\section{Introduction}

Despite their old origin (1953), glassceramic materials, as the products of mass technology under well-known names such as cerams, pyrocerams, vitrocerâmicos, vitroceramiques and sittals, remain popular objects of investigation [1]. These materials possess such typical property as thermoelasticity (in particular, residual stresses [2]), which is an object of intense interest in scientific circles, in the main. As is known, these materials can be obtained by means of bulk crystallization of glasses, consisting of one or several phases.

In the case of their uniform distribution in the glass phase, these substances are amorphous by structure and, consequently, isotropic from mechanical and optical aspects. However, one of the specifications for production is the cooling process that inevitably causes the non-uniform distribution of a temperature gradient [3]. In accordance with a heat conduction equation [4] the changes of temperature values in time and in volume of materials are accompanied by generation of mechanical stresses. Also, such structural transformations as crystallization, surface evaporation and diffusion of composition components cause residual stresses. These stresses always generate interest from both aspects, namely hardening and softening of material.

Typical examples of these media are glassceramics whose microstructure includes one or more crystalline phases dispersed in the glass matrix [5]. During measurements and diagnostics a package of physical and mechanical investigation methods, both nondestructive [6] and those based on the destruction of material, was used.

The process of manufacturing includes a set of stages. Among its main stages are cyclic heating (cooling) and corresponding phase transitions. Altogether, each of them is the subject of the special part of solid state physics, namely, thermoelasticity. The potential gradient (for a temperature or composition of a substance) induces the mechanical stress in these materials, which can be explained in general terms by inequalities of main tensor components, one of them being related to the gradient direction.

The consequence of this strained state is birefringence - a phenomenon used in tests and investigations of thermal stresses when applying the method of photoelasticity. This method was evolved long ago [7] and can be related to the category of nondestructive ones [8], which makes it irreplaceable when studying dynamics and kinetics of stresses. However, it is not the only version of the method described in classical monographs $[9,10]$. There is its update version whose perfection enabled us to find thin residual stresses in materials of the ZERODUR kind where these stresses must be definitely absent [11].

In this case we deal with the method of modulation polarimetry (MP) whose detectivity is unsurpassed in relation to induced birefringence caused by a directed strain. Therefore, the task of this work was to investigate restructuring processes 
in glassceramics in various annealing modes, and we hope that using the MP method will permit us to gather new data on these processes.

\section{Experimental Method}

The optical scheme of our facility is shown in Fig. 1. We used the alternatives of a semiconductor laser with linearly polarized radiation of the wavelength $\lambda=650 \mathrm{~nm}$, as a light source, and a diffraction monochromator with an input halogen lamp and the output polarizer.

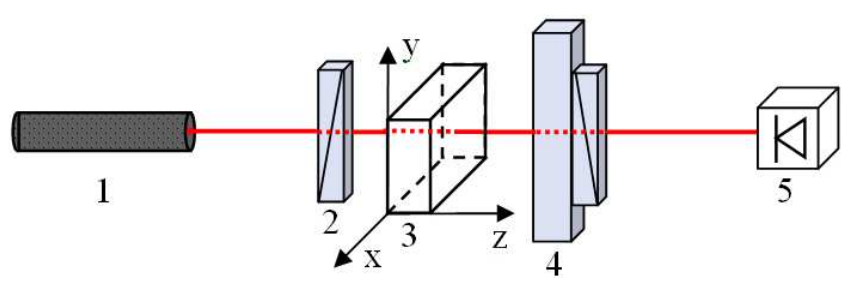

Figure 1. Optical scheme of the facility: 1 - semiconductor laser; 2 -linear polarizer; 3 -sample; 4 -polarization modulator; 5 -photodetector.

The polarization state was chosen as the initial one in consideration of the fact that when radiation propagates through the anisotropic sample its polarization is generally transformed to the elliptical one. A circular component appearing in a light beam served as a measure of birefringence, which according to Hooke's law is in proportion to the value of mechanical stress in the place of probing. It has been taken into account that according to the properties of the phase plate whose role is played by a sample under investigation, a precondition for the efficient transformation of linear polarization into the circular one is the angle of $45^{\circ}$ of the wave field $\vec{E}$ azimuth relative to the optical axis of a sample (direction of the strain).

Orientation of the optical axis is determined by the temperature gradient (i.e. a heat flux) that appears in the process of cooling the glassceramics sample. It is perpendicular to the surfaces of the ingot (y-coordinate). Therefore, in accepted Stokes vector designations [12], the falling of radiation on the sample traces its U-component. The $\mathrm{V}$-circular component of elliptically polarized radiation at the sample output has the value $\mathrm{V}=\mathrm{U}^{*} \sin \varphi[13]$. In this case, $\varphi$ is the phase difference between orthogonal linear components of radiation, which in the lab coordinates of Fig. 1 is determined by the relation $\varphi_{\mathrm{y}}=(2 \pi / \lambda) \mathrm{dC} \sigma[14]$, where $\lambda$ is the wavelength of probing radiation, $\mathrm{d}$ - sample thickness, $\mathrm{C}$ - stress optic coefficient, $\sigma-$ mechanical stress. Thus, when anisotropy has low values (phase delay is $\sin \varphi=\varphi$ ), the value of $\mathrm{V}$-component is a linear measure of birefringence and the value of the difference between diagonal elements $\sigma_{\mathrm{x}}$ and $\sigma_{\mathrm{y}}$ inherent to the tensor of mechanical stress in the z-plane

$$
\mathrm{V}=\mathrm{U}^{*}(2 \pi / \lambda) \mathrm{dC} \sigma
$$

Characteristics of the analysis of the polarization state of radiation, using polarization modulation, were under due consideration in [13] where it was shown that elliptically polarized radiation generates signals with multiple frequencies in a photodetector (Si photodiode). In the present case, when determining the value of a circular component with modulation frequency, we used the method of measurements "from zero". The fact that circular polarization is absent in the initial probing radiation widens substantially the range of registration of its value. We registered the $\mathrm{V}$ value by means of the two alternative methods: line-by-line scanning of the $\mathrm{z}$-surface in the $\mathrm{x}$-direction to obtain tomography, as well as scanning along the $\mathrm{y}$-coordinate at the level $\mathrm{x} \approx 25 \mathrm{~mm}$ to calculate the relevant coordinate distribution of the stress optic coefficient. This method is based on a polarized light transmission through a transparent sample. So, stresses become integrated along the whole thickness of the sample while the signal, which sums up stresses of interior layers, is registered. The nonuniform space distribution of the composition (defects) deviates generally the chemical potential from linear gradient that causes residual stress in accordance with the Poisson's equation.

In the work, we used samples cut from the lithium-aluminosilicate glass ingot in the direction perpendicular to the free glass surface. Investigated were the rectangular plates of the dimensions $x \times y \times z=50 \times 30 \times 20(\mathrm{~mm})$, their z-surface being polished up to the state of minimum light scattering. Therefore, the azimuth of the electric field $\vec{E}$ for the wave falling on the sample was set at an angle of $45^{\circ}$ relative to its $\mathrm{x}, \mathrm{y}$-coordinate axes. Two-coordinate probing of the z-plane, which runs parallel to the direction of a heat flux appearing when the ingot is cooled, has enabled us to obtain the tomogram for the value and sign of uniaxial stress.

The evolution of stresses was under study after two-hour annealing both in the step-by-step process (temperatures ranged from $600{ }^{\circ} \mathrm{C}$ to $950{ }^{\circ} \mathrm{C}$ with the step of $50^{\circ} \mathrm{C}$ ) as well as in the one-time process $\left(700{ }^{\circ} \mathrm{C}\right.$ and $\left.900{ }^{\circ} \mathrm{C}\right)$. Annealing was performed in a muffle furnace (stability of temperature during the steady-state behavior was $\pm 2{ }^{\circ} \mathrm{C}$ ) in the ambient air. To avoid sticking of foreign particles to the polished surface of samples under study, the samples were placed into a container with a cover made of the same material. This technique provided additional thermal stabilization and decreased the influence of convection currents in a chamber of the furnace. After annealing, the sample, together with the furnace, has been cooling to room temperature for no less than 20 hours.

\section{Results and Discussion}

Considering the results of research, we shall take into account that the cause of residual stresses in glass and glassceramics lies in non-uniformity of their composition that is due to action of several factors: a viscoelastic flow at high temperatures and elasticity of material at lower temperatures, relationships between the values of internal and surface crystalline phases, different thermoelasticity of phases, the availability of temperature gradients when heating and cooling the sample. When estimating the spatial distribution of the mechanical properties of products made from glassceramics, it should be also borne in mind that the stresses resulting from thermal treatment can be both local and rather extended. In 
particular, near-surface strains of "chemical origin" can considerably differ from the residual ones in the middle of the plate in their values [3].

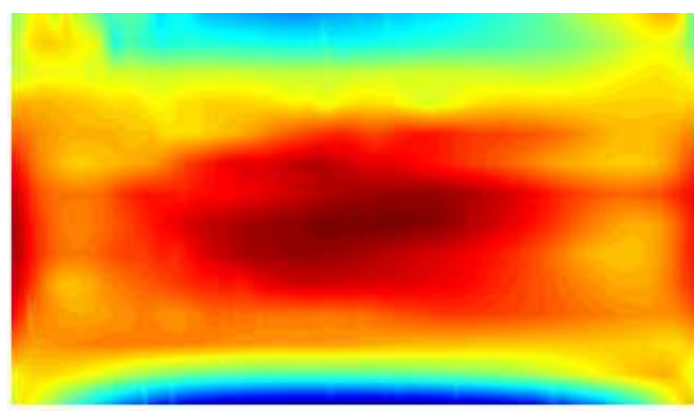

a) initial material

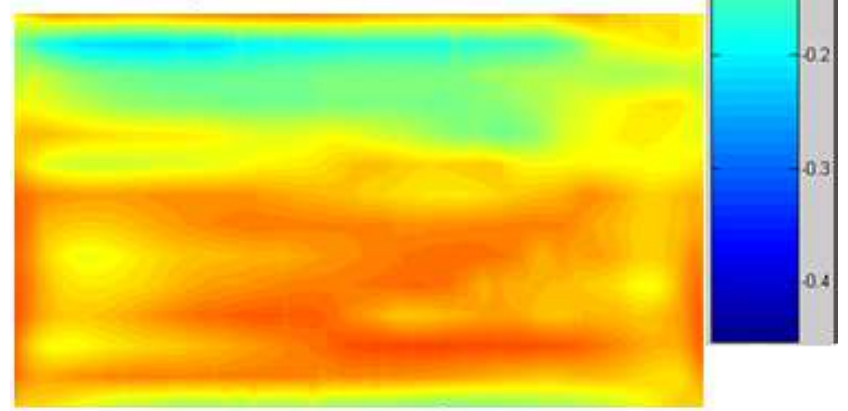

b) $700{ }^{\circ} \mathrm{C}$

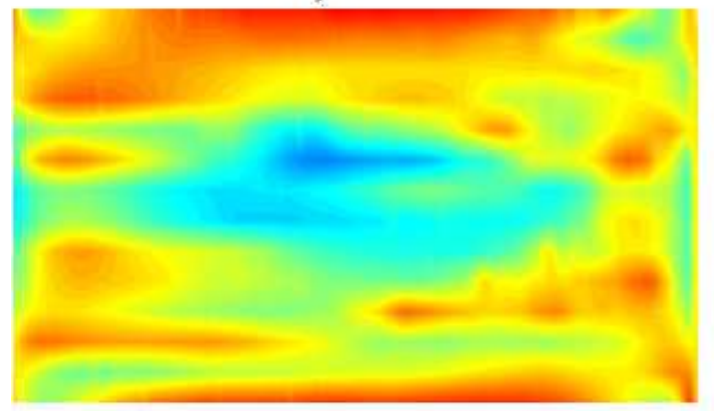

c) $850{ }^{\circ} \mathrm{C}$

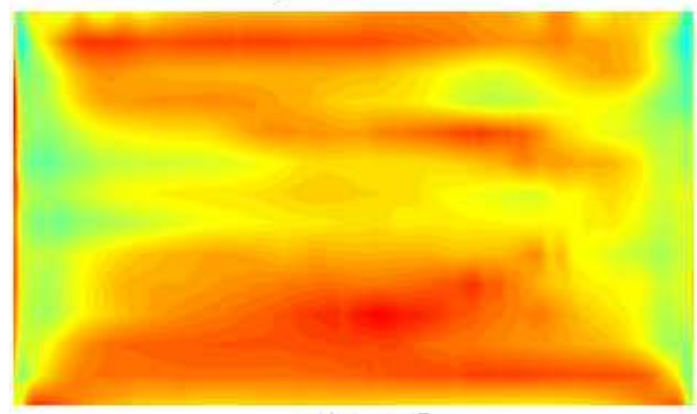

d) $950^{\circ} \mathrm{C}$

Figure 2. Evolution of residual stresses in the initial sample and in that annealed at the temperatures of 700,850 and $950^{\circ} \mathrm{C}$.

The above statement is well illustrated by the tomograms of stresses obtained experimentally in this work for the step-by-step process of annealing. They are represented in Fig. 2 for the sample in the initial state and after annealing at the temperatures of 700,850 and $950^{\circ} \mathrm{C}$. As is clear from the drawing, the sample in the initial state (Fig. 2a) has the largest stresses, which is typical of industrial ingots after their cooling and solidification in conditions of the temperature gradient. It is one of the reasons that leads to the compression of near-surface layers (both top and bottom) along the $\mathrm{x}$-coordinate and extension in the center of the plate. Two-hour annealing at a temperature of $600^{\circ} \mathrm{C}$ changes neither the value nor the distribution of internal mechanical stresses in the sample.

Successive annealing at the temperatures of 650,700 (Fig. 2b) and $750{ }^{\circ} \mathrm{C}$ results in a decrease in stress values and a more uniform distribution of residual stresses. The tomograms of stresses in the samples annealed at the temperatures of 800,850 (Fig. 2c), $900{ }^{\circ} \mathrm{C}$ demonstrate their gradual increase and the opposite pattern of the spatial distribution relative to the initial one. The experimental results have shown that the change from the compression strain to the extension one along the $\mathrm{x}$-coordinate in the near-surface region of a sample is due to a phase transition in glass as a result of the appearance of the crystalline lithium-aluminosilicate component. Annealing of the sample at a temperature of $950^{\circ} \mathrm{C}$ (Fig. $2 \mathrm{~d}$ ) resulted in the considerable decrease of stresses and more uniform distribution in their value.

A more specific notion about the spatial evolution of stresses can be got from Fig. 3 in which stress dependences for $\sigma=\sigma_{x}-\sigma_{y}$ are expressed numerically as sections of topograms in Fig. 2 with the coordinate $\mathrm{x}=2.5 \mathrm{~cm}$. The largest stresses take place in the initial sample. It has been already assumed in [3] that their origin can be of double nature. First of all, it is the so-called "chemical" thermoelasticity arising in the process of stretching the ingot in a thin near-surface layer, which relates to changes in the composition of a substance. Its compression energy is localized in the thin subsurface layer whose strain can propagate at a microscopic distance. Further, residual stresses take place because of the non-uniform composition of the sample material along the y-coordinate. As to the asymmetry of the $\sigma(y)$ function inherent to the initial sample, its external cause lies in different mechanisms of heat removal when cooling the plate - it is convective from the side of a free surface and conductive from the side of an underlying surface. The $\mathrm{x}$-direction is of less interest to us because of the influence of machining of facets on residual stresses.

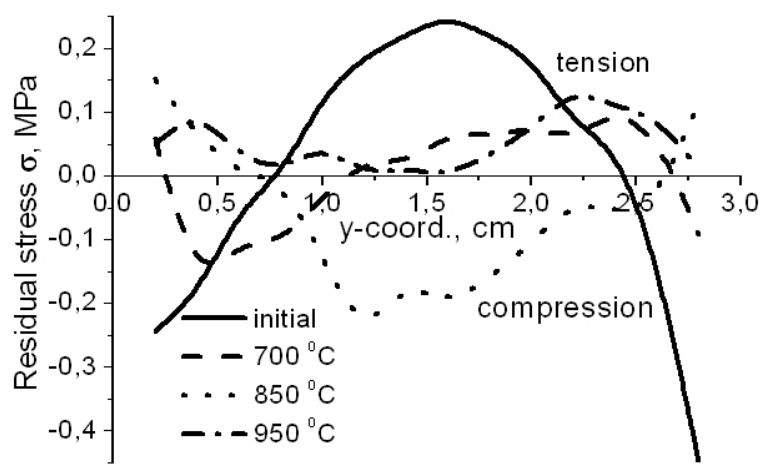

Figure 3. Residual stresses along the y-coordinate in the initial and annealed samples. 


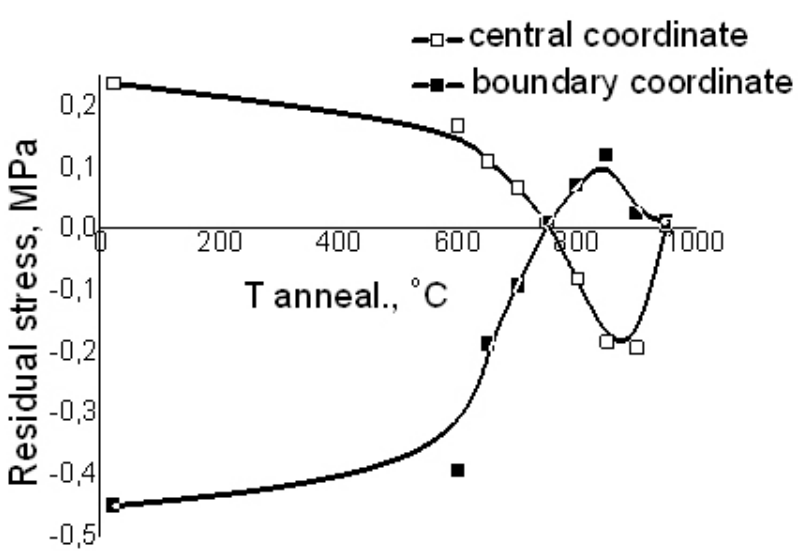

Figure 4. Residual stress versus the annealing temperature in the center of the sample $(y=1.5 \mathrm{~cm})$ and on its periphery $(y=2.75 \mathrm{~cm})$.

The evolution of the value of residual stresses with the annealing temperature is diverse. Fig. 4 shows the alternatives, which trace clearly three stages: the first stage with slight gradient of the temperature to $600{ }^{\circ} \mathrm{C}$; at the second stage, there was sharper gradient, the temperature ranging from $650{ }^{\circ} \mathrm{C}$ to $850{ }^{\circ} \mathrm{C}$; and at the third stage, there was also sharp gradient but it had the opposite sign within the range of $850 \ldots 950{ }^{\circ} \mathrm{C}$. According to the data [14], annealing of lithium-aluminosilicate glass is usually performed at temperatures ranging from $670{ }^{\circ} \mathrm{C}$ to $690{ }^{\circ} \mathrm{C}$, since the optimum temperature for creating crystallization centers $\mathrm{T}_{\mathrm{opt}}$ is 50 degrees higher than these values. It is the second stage that corresponds to the crystallization process, leading to substantial changes in stresses, even to changes in their sign relative to the initial one.

These internal residual stresses occur in glassceramics in the course of cooling, which is due to a disparity in the coefficients of thermal expansion and elasticity of crystalline and vitreous phases as well as the non-uniform distribution of the latter. The third stage, namely annealing at a temperature of $950{ }^{\circ} \mathrm{C}$, has led to a sharp drop in the values of residual stresses, which can be explained by the assumption that the crystallization process in the whole bulk of material was fully completed at lower temperatures.

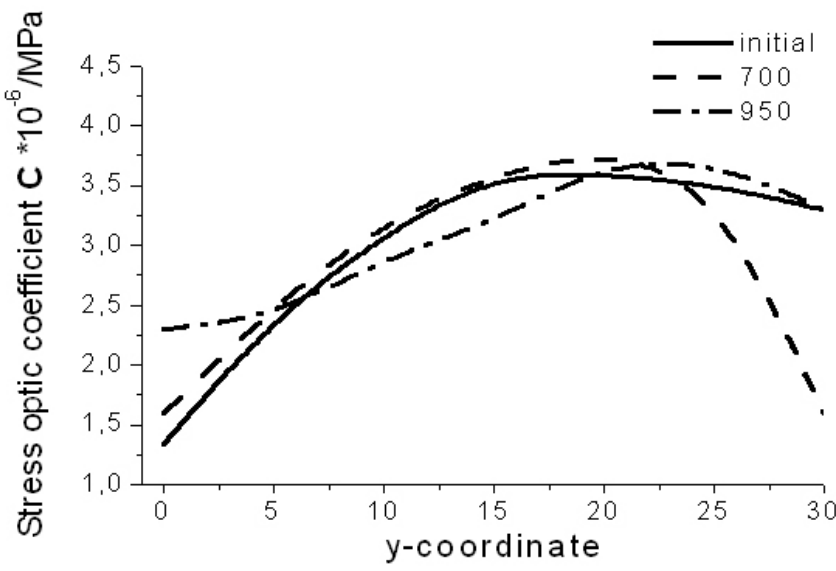

Figure 5. Stress optic coefficient values along the y-coordinate for $x=2.5 \mathrm{~cm}$, which were determined for the initial and annealed glassceramic samples at the temperatures of 700 and $600 \ldots 950^{\circ} \mathrm{C}$.
It is known [15] that the coordinate distribution of the chemical potential $\varphi(y)$ (i.e. composition) and residual stresses induced by it are qualitatively related. This relation can be expressed as the Poisson equation: $d^{2} \varphi / d y^{2}=\sigma / \eta$ (where $\eta$ is the coefficient of proportionality). In the absence of temperature gradient, the potential can be expressed through the energy of a glassceramics system. This energy is determined by the ratio of system components. In that case, a physical expression of this ratio can include the stress optic coefficient C. Indeed our experiments show that the stress optic coefficient depends on coordinates as well as on the annealing process in a complicated way (Fig. 5).

Besides, its mean value exceeds essentially (1.5 ...2 times) the corresponding value of silica glass, which is indicative of the crystalline phase in material under study.

As is clear from Fig. 5, non-uniformity in the composition of a substance can take place both in the initial sample and in that exposed to intermediate annealing. And only heating to a temperature of $950{ }^{\circ} \mathrm{C}$ can equalize its composition to some extent. At the same time, Fig. 3 shows a correlation between the $\mathrm{C}(\mathrm{y})$ curves tending to decrease the values of non-uniformity of the composition and the values of residual stresses. To represent it rigorously, let us collate the left side of the above Poisson equation with the right one. Choosing between the double differentiation of the potential and double integration of the stress function, let us use the latter, as it is less prone to the influence of experimental errors.

Fig. 6 shows the result of integration under boundary conditions making these integrals definite in comparison with the coordinate function $\mathrm{C}(\mathrm{y})$. Stresses of the unannealed sample (Fig. 2) are essentially asymmetric that is due to the asymmetry of cooling mechanisms (the contact mechanism at the bottom and the convective+radiation mechanism at the top). The noise-signal relation $\& 100 \mathrm{~Pa} / 10^{6} \mathrm{~Pa}$ testifies of authenticity of the results of measurements.

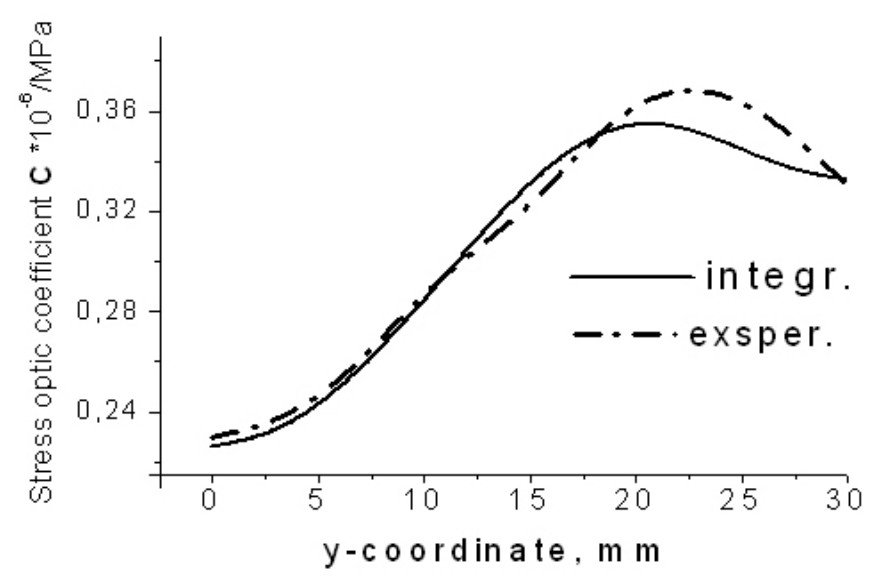

Figure 6. Dependence of the stress optic coefficient values on the $y$-coordinate for the annealed sample $\left(T=950{ }^{\circ} \mathrm{C}\right)$ and that obtained by means of double graphic integration of the corresponding curve in Fig. 3.

The curve in the case $\mathrm{T}=950{ }^{\circ} \mathrm{C}$ was chosen because surface gradient of the potential practically disappears at this temperature, and so does its inevitable contribution to stress 
from a bulk source. More than satisfactory fitting of the curves confirms the validity of the above assumptions.

\section{Conclusions}

Residual stresses in the ingot of lithium-aluminosilicate glassceramics have been under study, using the method of modulation polarimetry. The gist of the method is registration of the circularly polarized component of radiation, which arises when radiation propagates through a transparent dielectrically anisotropic sample. The value of this component to a linear approximation is determined by birefringence induced by thermoelasticity and can be used as its measure. Within the plane running parallel to temperature gradient, thermal stresses have been depicted as 2D topological and functional representations. Their spatial dependences show relaxation of the stresses under heating in a complex way. Additional measurements of the spatial distribution inherent to the stress optic coefficient have helped find its correlation with the stress function, which agrees with the appearance of the crystalline phase in the composition of glass.

\section{References}

[1] E. D. Zanotto. A bright future for glassceramics. American Ceramic Society Bulletin. Vol. 89, No. 8, pp. 19-27 (a review).

[2] T. Alts, P. Strehlow. Frozen deformations, frozen stresses, and structure-induced $\mathrm{Na}$ distributions in sodium-silicate glasses. Journal of Thermal Stresses. Volume 7, Issue 3-4, 1984, pp. 317-359.

[3] S. Karlsson, B. Jonson, C. Stelhandske. The technology of chemical glass strengthening (a review). Eur. J. Glass Sci. Technol. A, April 2010, 51 (2), pp. 41-54.

[4] Unsworth, J. \& Duarte, F. J. (1979). Heat diffusion in a solid sphere and Fourier Theory. Am. J. Phys. T. 47 (11), pp. 891-893.
[5] V. R. Mastelaro, E. D. Zanotto. Residual stresses in a soda-lime-silica glassceramics. Journal of Non-Crystalline Solids 194 (1996), pp. 297-304.

[6] B.D. Cullity. Elements of X-ray diffraction, diffracted beam of monochromatic X-rays, 2nd Ed. (Addison-Wesley, Reading, MA, 1978) p. 292.

[7] D. Brewster. Philosophical Transactions. R. Soc. Lond. 1815 105, pp. 29-53.

[8] J. R. Lesniak, M. J. Zickel, D. J. Bazile, B. R. Boyce. Assessment of Grey-Field Photoelasticity. Proceedings of the 1999 SEM Spring Conference on Experimental Mechanics, Cincinnati, OH, June 7-9, 1999. pp. 198-211.

[9] E. Coker, L. Filon. A Treatise on Photo-Elasticity. Cambridge University Press. 1931, p. 720.

[10] Max Mark Frocht. Photoelasticity. Volume I, II, 1948, p. 523.

[11] I. Minailova, I. Matyash, B. Serdega, V. Maslov, N. Kachur. Research on thermoelastic tension in two-layer structure of glassceramic ZERODUR by modulation polarimetry method. International Journal of Nano Research and Application 2014; 2(5), pp. 93-97.

[12] M. Born, E.Wolf. Principles of optics. Cambridge University Press, Cambridge (1968), p. 952.

[13] L. I. Berezhinsky, I. L. Berezhinsky, V. I. Pipa, B.K. Serdega. Semiconductor Physics, Quantum Electronics \& Optoelectronics. 2007, V.10, No. 1, p. 49.

[14] V. R. Mastelaro, E. D. Zanotto. Anisotropic residual stresses in partially crystallized Li2O-2SiO2 glassceramics. Journal of Non-Crystalline Solids 247 (1999), pp. 79-86.

[15] R. P. Feynman, R. B. Leigton, M. Sands. The Feynman lectures on physics. Addison-Wesley Publishing Company, Inc. Reading, Massachusetts, Palo Alto, London. 1964, p. 1552. 